\title{
Treatment of a Polysulphide Ore by Ammoniacal \\ Thiosulfate Solutions and Ion Flotation for Gold
}

\section{Recovery}

\author{
Sebastián Gámez and Ernesto de la Torre \\ Faculty of Chemical Engineering and Agro-industry, Extractive Metallurgy Department, Escuela Politécnica Nacional, Quito EC \\ 17012759, Ecuador
}

\begin{abstract}
Ammoniacal thiosulfate solutions with cupric ions have proved to be more successful than cyanidation in handling complex ores like carbonaceous and cuprous minerals. That's why cyanidation and ammoniacal thiosulfate leaching was performed at $33 \%$ of solids concentration in order to compare the efficiency of both techniques. Cyanidation delivered a gold recovery of $80.6 \%$ at 24 hours of agitation, whereas ammoniacal thiosulfate leaching achieved an $80.9 \%$ of gold recovery in only one hour of agitation. Then, the ammoniacal thiosulfate solutions obtained were submitted to five gold recovery techniques (carbon adsorption, cementation, adsorption on carbon impregnated with metallic copper, ion flotation and electrolysis) in order to determine which one of them was the most effective technique. Ion flotation proved to be the best technique due to its gold recovery of $84 \%$. In addition, this technique only required trioctyl methyl ammonium chloride (Aliquat) and FloMin F-121 in a 0.1\% concentration inside the solution. The small amounts of the flotation reagents allow the flotation concentrate to be treated by electrolysis. It was performed with $1.5 \mathrm{~V}$ during three hours and the resulting gold recovery was $82 \%$ in the cathode zone.
\end{abstract}

Key words: Ammoniacal thiosulfate leaching, ion flotation, electrolysis.

\section{Introduction}

Gold dissolution by ammoniacal thiosulfate solutions is an alternative process that can handle complicated refractory ores [1]. It is important to mention that thiosulfate ion by itself cannot dissolve gold as fast as cyanide does so; aqueous ammonia and cupric ions in form of copper sulfate must be added to catalyze gold dissolution [1-3]. In addition, this leaching process is formed by a joint of redox reactions which drive to the formation of gold-thiosulfate complex. Leaching begins when aqueous ammonia and cupric ions form the copper (II) tetra-amine which is the responsible to accelerate gold dissolution $[1,4]$.

$$
\begin{array}{r}
\mathrm{Au}^{0}+\left[\mathrm{Cu}\left(\mathrm{NH}_{3}\right)_{4}\right]^{2+}+3 \mathrm{~S}_{2} \mathrm{O}_{3}^{2-} \rightarrow \\
{\left[\mathrm{Au}\left(\mathrm{NH}_{3}\right)_{2}\right]^{2+}+\left[\mathrm{Cu}\left(\mathrm{S}_{2} \mathrm{O}_{3}\right)_{3}\right]^{5-}+2 \mathrm{NH}_{3}}
\end{array}
$$

Corresponding author: Sebastián Gámez, chemical engineer, research field: leaching of polysulphide ores. E-mail: zebaz_1991@hotmail.com.
Diamino aurous reagent, which was formed in the last reaction, reacts with thiosulfate ion forming the gold-thiosulfate complex.

$$
\begin{gathered}
{\left[\mathrm{Au}\left(\mathrm{NH}_{3}\right)_{2}\right]^{2+}+\underset{2}{2 \mathrm{~S}_{2} \mathrm{O}_{3}^{2-}} \rightarrow\left[\mathrm{Au}\left(\mathrm{S}_{2} \mathrm{O}_{3}\right)_{2}\right]^{3-}+} \\
2 \mathrm{NH}_{3}
\end{gathered}
$$

At the same time, cuprous ions are oxidized again due to the presence of dissolved oxygen and then copper (II) tetra-amine appears in the solution as a result of cuprous ions oxidation.

$$
\begin{gathered}
4\left[\mathrm{Cu}\left(\mathrm{S}_{2} \mathrm{O}_{3}\right)_{3}\right]^{5-}+16 \mathrm{NH}_{3}+\mathrm{O}_{2}+2 \mathrm{H}_{2} \mathrm{O} \rightarrow \\
4\left[\mathrm{Cu}\left(\mathrm{NH}_{3}\right)_{4}\right]^{2+} 12 \mathrm{~S}_{2} \mathrm{O}_{3}^{2-}+4 \mathrm{OH}^{-}
\end{gathered}
$$

Finally, the global reaction is:

$$
\begin{array}{r}
4 \mathrm{Au}^{0}+8 \mathrm{~S}_{2} \mathrm{O}_{3}^{2-}+\mathrm{O}_{2}+2 \mathrm{H}_{2} \mathrm{O} \rightarrow \\
4\left[\mathrm{Au}\left(\mathrm{S}_{2} \mathrm{O}_{3}\right)_{2}\right]^{3-}+4 \mathrm{OH}^{-}
\end{array}
$$

Although thiosulfate leaching is as effective as cyanidation is, it has not had an industrial development. The main reason lies on the difficulty of extract gold from thiosulfate liquors [1]. Even the conventional process of carbon adsorption is useless for this purpose. 
In the last years, resin adsorption has become the most promosing technique for gold recovery. However, its high cost of enforcement and regeneration does not allow engineers to consider it as a practical way of gold recovery. The low affinity of thiosulfate towards activated carbon surface carries to low gold recovery from thiosulfate liquors $[1,5]$. Nevertheless, an increase in $\mathrm{pH}$ solution could improve carbon adsorption performance [6].

It is essential to point out that the presence of aqueous ammonia can raise solutions $\mathrm{pH}$. If aqueous ammonia is present in more quantity than thiosulfate, diamine aurous (I) complex concentration will increase [7]. This gold-amine complex has more affinity for activated carbon than gold-thiosulfate and gold recovery could increase consequently. Nevertheless, in order to recovery higher amounts of gold, activated carbon concentration must increase as well but gold loading on carbon will be too low [5].

The precipitation of gold is another technique for gold recovery from solutions. The main precipitants used in this process are zinc and copper whose electrochemical difference with gold permits gold to precipitate in form of zerovalent metal [1]. It is important to note that the metallic precipitant may reduce thiosulfate which will drive to the passivation of the available area for gold precipitation [1]. Also, high cupric ions concentration could decrease gold recovery due to its reduction and further passivation of metallic copper area, especially when solution $\mathrm{pH}$ is below 10.0 $[8,9]$.

In solvent extraction, the solution is in contact with an organic phase which holds an adequate extractant diluted in an organic solvent [1]. Many extractants have been proved in the last years by adjusting solutions $\mathrm{pH}$ in order to get higher recoveries of gold in the organic phase. The most successful extractant was trioctyl methyl ammonium chloride (Aliquat) which does not need a $\mathrm{pH}$ adjustment for its use in solvent extraction process [10]. The problem of this technique lies on the extraction of gold from the organic phase for further gold recovery.

Gold electrodeposition from ammoniacal thiosulfate solutions, by application of a direct current, presents various hardships. For instance, the presence of cupric ions could contaminate the metallic product obtained by the reduction of gold-thiosulfate complex in the cathode area [1]. Another issue is the high consumption of direct current due to parallel and parasitic reactions like the reduction of water and dissolved oxygen in the cathode area [6]. Therefore, the product obtained must be refined in order to get metallic gold.

\section{Experiment}

\subsection{Mineral Characterization}

Chemical ore composition was found by acid digestion and fire assays. The obtained samples were analyzed by atomic absorption spectrophotometry in Perkin AA300. The mineralogical composition was determined by x-ray diffraction in Bruker D8 Advance. Finally, the mineral with a $d_{100}=2 \mathrm{~mm}$ was grounded with a ball mill with $62.5 \%$ of solids for 37 minutes in order to obtain a $d_{80}$ of $100 \mu \mathrm{m}$.

\subsection{Ammoniacal Thiosulfate Leaching}

In all ammoniacal thiosulfate leaching processes the solution was prepared and then stabilized at $\mathrm{pH}$ of 10.5 by adding aqueous ammonia. Sodium thiosulfate of $95 \%$ of purity was used and $20 \%$ of aqueous ammonia as well. Cupric ions were introduced in form of copper sulfate pentahydrate. The ore was added in the liquor in order to achieve a given density pulp of $33 \%$ of solids. The agitation speed was maintained at 1,500 rpm in all experiments and samples from the pulp were taken during each one. Samples were analyzed by atomic absorption spectrophotometry in order to determine the gold recovery in the solution.

Also, the iodometric technique was employed in order to determine the concentration of thiosulfate during the tests. It consisted in adding the clarified sample into an iodine solution up to it changed from black to yellow. Then, three drops of starch solution 
were added up to the iodine solution became colorless. The spent sample volume was measured for determining the amount of thiosulfate that was needed to add into the pulp. Once an experiment finished, the pulp was filtered in a press filter. The solutions were measured and stored for further experiments. Tailings were submitted to fire assay for determining the amount of gold that did not dissolve.

\subsection{Cyanidation}

In cyanidation process, water was introduced in a stirred vessel in order to prepare the liquor for the leaching. The ore was introduced inside the vessel for achieving a density pulp of $33 \%$. Then, technical sodium cyanide was added up to a concentration of 1 $\mathrm{g} / \mathrm{L}$ was accomplished. Immediately, lime was added in order to increase $\mathrm{pH}$ solution above 10.5. After that, the agitation begun and during 24 hours, samples were obtained from the solution for gold analysis by atomic absorption spectrophotometry. The argentometric test, which consisted in adding a silver nitrate solution into a clarified sample, was employed in order to determine the quantity of cyanide required in every moment by measuring the volume of silver nitrate solution spent. Once cyanidation finished, the pulp was filtered in press filter. The solution was measured. Tailings were submitted to fire assay for determine the amount of gold that did not dissolve.

\subsection{Gold Recovery by Adsorption on Activated Carbon and Activated Carbon Impregnated by Metallic Copper}

In these tests, activated carbon with $2 \mathrm{~nm}$ of pore size, $523 \mathrm{~m}^{2} / \mathrm{g}$ of surface and a size range of $4.7-2.3$ $\mathrm{mm}$ was employed inside a stirred vessel. Only the clarified solutions from thiosulfate leaching process were used. The agitation speed was maintained below $500 \mathrm{rpm}$ in order to avoid activated carbon rupture. Samples were taken at different times for further gold analyses by atomic absorption spectrophotometry. The same procedure was performed with activated carbon impregnated with metallic copper.

\subsection{Cementation}

In these kinds of tests, copper powder with $38 \mu \mathrm{m}$ of size was employed. Equally, clarified solutions from the thiosulfate leaching process were introduced in vessels at a stirred speed of 1,500 rpm. Samples were taken at different times for further gold analyses by atomic absorption spectrophotometry.

\subsection{Ion Flotation}

Clarified solutions from thiosulfate leaching were used. $100 \%$ Aliquat was employed as collector and 1\% FloMin F-121 was used as foaming reagent. Both flotation reagents were applied to $0.1 \%$ concentration inside solutions. Ion flotation tests were developed during 40 minutes and the ion flotation concentrated (froth) was gathered as it overflowed from the flotation cell.

\subsection{Electrolysis}

Electrolysis tests were applied to thiosulfate clarified solutions as well as ion flotation concentrates in order to determine the feasibility of this technique in both currents. Also, the addition of sodium sulfite was evaluated as thiosulfate stabilizer. This process was developed in a plastic cell with $200 \mathrm{~mL}$ of capacity. Stainless steel electrodes were employed in those experiments and voltage was modified from $0.4 \mathrm{~V}$ to $1.5 \mathrm{~V}$.

\section{Results and Discussion}

Agroheart mineral contains the following chemical composition presented in Table 1 [11].

Clearly, gold and silver are in a high amount inside Agroheart ore so this mineral is viable for gold extraction. Another feature is that iron and copper concentration inside the mineral is very low. Therefore, thiosulfate oxidation due to the presence of those metals would not be a serious problem. In addition, the mineralogical composition of Agroheart ore, showed in Table 2, demonstrates that the ore has only $1 \%$ of a sulfurized compound (Pyrite). So thiosulfate wouldn't 
Table 1 Chemical characterization of Agrocorazón ore.

\begin{tabular}{lcll}
\hline Element & Content & Element (\%) & Content \\
\hline $\mathrm{Au}(\mathrm{g} /$ ton $)$ & 10.9 & $\mathrm{Fe}$ & 0.9 \\
$\mathrm{Ag}(\mathrm{g} /$ ton $)$ & 25.9 & $\mathrm{Na}$ & 2.6 \\
$\mathrm{Mg}(\mathrm{g} /$ ton $)$ & 55.0 & $\mathrm{~K}$ & 0.9 \\
$\mathrm{Co}$ (g/ton) & 115.0 & $\mathrm{Cu}$ & 0.0 \\
\hline
\end{tabular}

Table 2 Mineralogical composition of Agrocorazón ore.

\begin{tabular}{ll}
\hline Compound & Content (\%) \\
\hline Quartz & 75 \\
Kaolinite & 12 \\
Poligoskite & 5 \\
Muscovite & 5 \\
Clinochlore & 2 \\
Pyrite & 1 \\
\hline
\end{tabular}

be oxidized to another compound since the amount of sulfides is low [11].

\subsection{Comparison between Cyanidation and} Ammoniacal Thiosulfate Leaching

Both leaching processes were developed with a pulp density of $33 \%$ and the gold recovery in the solutions can be observed in Fig. 1.

Gold recovery obtained in cyanidation at 24 hours of agitation was of $80.6 \%$ whereas in ammoniacal thiosulfate leaching, a gold recovery of $80.9 \%$ was accomplished. With a pulp density of $33 \%$ of solids, both gold recoveries were similar; however, in ammoniacal thiosulfate leaching the gold dissolution was got at one hour of agitation. Evidently, ammoniacal thiosulfate leaching is faster than cyanidation process but, it is necessary to accomplish an adequate equilibrium between the leaching reagents. It is imperative to find the quantities of the leaching reagents required to obtain the highest gold recovery in thiosulfate solutions.

\subsection{Evaluation of Processes Employed for Gold}

\section{Recovery from Ammoniacal Thiosulfate Liquors}

The biggest problem related with ammoniacal thiosulfate leaching is the recovery of gold from its solutions. In this work, five techniques were used in order to determine which one of them is the best for gold

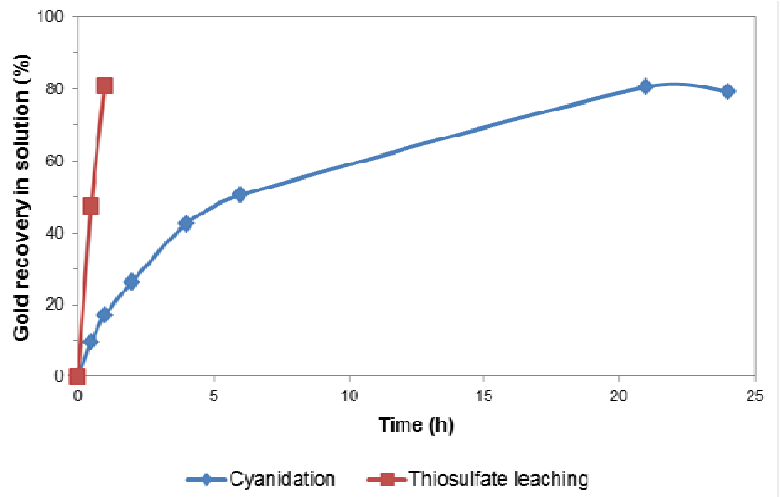

Fig. 1 Gold recovery in cyanidation ( $33 \%$ solids; $\mathrm{pH}=10.5$; [CNNa] $\left.=1 \mathrm{~g} / \mathrm{L} ; d_{80}=100 \mu \mathrm{m}\right)$ and ammoniacal thiosulfate leaching ( $33 \%$ solids; $\mathrm{pH}=10.5 ;\left[\mathrm{Na}_{2} \mathrm{~S}_{2} \mathrm{O}_{3}\right]=1.5 \mathrm{M}$; $[\mathrm{Cu}]=2$ $\left.\mathrm{mM} ; d_{80}=100 \mu \mathrm{m}\right)$.

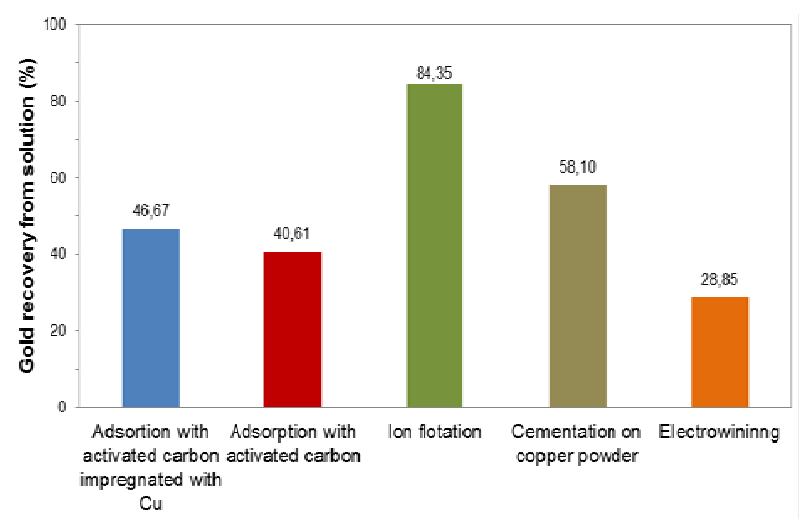

Fig. 2 Comparison between employed techniques for gold recovery from ammoniacal thiosulfate leachates.

recovery from ammoniacal thiosulfate solutions. In Fig. 2 , the optimal results of gold recovery obtained in each employed method are shown.

The most successful recovery process was ion flotation whose gold recovery was of $84 \%$. In contrast, the worst recovery technique was electrolysis due to its poor gold recovery. In electrolysis, a direct current of $0.4 \mathrm{~V}$ was applied during one hour. In addition, a gold recovery of $28 \%$ was achieved with the formation of a black precipitate on the cathode zone. Gold cementation with copper powder was tested too. The experiments were developed during two hours without the presence of air due to copper surface passivation. Nevertheless, copper powder was useless since a low gold recovery on copper surface was accomplished. This technique is problematic due to cupric ions competes against gold to precipitate on copper powder 
surface. Besides, copper (II) tetra-amine dissolves the precipitated gold once it is on copper surface. However, cementation on copper powder provides a higher gold recovery than gold adsorption on activated carbon.

In activated carbon adsorption processes, a gold recovery of $40 \%$ was obtained due to the low affinity that exists between gold-thiosulfate and activated carbon surface. In order to improve activated carbon performance, it was impregnated with metallic copper by electrodeposition. The intention was to improve the affinity between gold-thiosulfate and activated carbon by adding metallic copper which acts as a precipitant. However, a significant improvement was not possible because the gold recovery on activated carbon impregnated with metallic copper was just of $46 \%$. Perhaps, the non-uniformity copper layer covered the activated carbon pores so its superficial area was reduced as a result of that. Then the spaces for gold-thiosulfate precipitation were not available. In addition, the same problems that affect gold cementation of copper powder could affect this technique.

\subsection{Ion Flotation of Gold from Ammoniacal Thiosulfate} Solutions

Fig. 3 shows gold recovery obtained in the froth by ion flotation technique.

The ion flotation experiments were driven during 40 minutes and at the end, a gold recovery in the froth of $84 \%$ was achieved. Another aspect to notice is that the cumulative volume was of $59 \%$. The success of this process lies in the affinity between Aliquat (quaternary amine) and gold-thiosulfate. Aliquat acts as a collector, it means that its hydrophobic part sticks to ascending air bubbles whereas its hydrophilic part joints to gold-thiosulfate complex. Therefore, gold-thiosulfate ascends toward flotation cell surface and the precious metal is concentrated in form of froth. The resulting froth is still aqueous since the concentration of the flotation reagents is very low. For that reason, it is not necessary the application of re-extraction step in order to separate the gold from the organic phase. The ion flotation concentrate (froth) was submitted to electrolysis in order to determine if it is possible to extract gold by this technique.

\subsection{Electrolysis Test}

In Fig. 4, gold recoveries from ammoniacal thiosulfate solutions with and without sodium sulphite are plotted.

Electrolysis tests were developed with the presence of sodium sulphite at $0.1 \mathrm{M}$ of concentration in ammoniacal thiosulfate solutions in order to determine if the mentioned reagent could stabilize the gold-thiosulfate complex. Thus, gold-thiosulfate did not precipitate as gold sulfide on the cathode zone during the development of this experiment. It could be

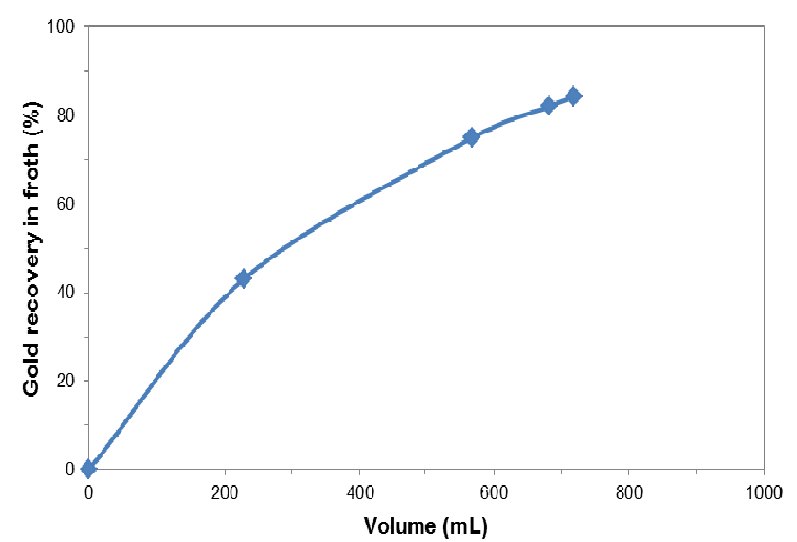

Fig. 3 Gold recovery by ion flotation (time $=\mathbf{4 0} \mathrm{min} ; \mathbf{p H}=$ $10 ; 100 \%$ Aliquat as collector and $1 \%$ Flomin F-121 as foaming reagent).

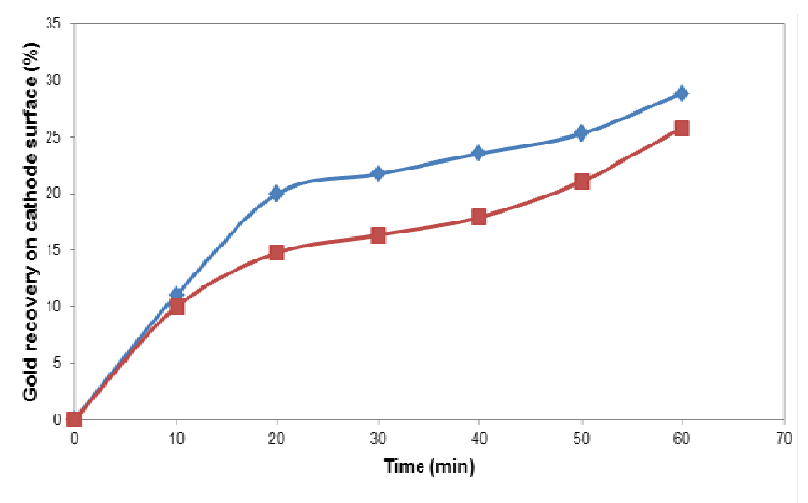

Fig. 4 Gold recovery from solutions without sodium sulphite (0.4 V; $12.6 \mathrm{~mA}$; $\mathbf{p H}=10)$ and with sodium sulphite $\left(0.4 \mathrm{~V} ; 12.6 \mathrm{~mA} ; \mathrm{pH}=10 ;\left[\mathrm{Na}_{2} \mathrm{SO}_{3}\right]=0.1 \mathrm{M}\right)$. 
noticed that gold recoveries were very low even gold sulfide formation was avoided. With the presence of sodium sulphite gold did not deposit on stainless steel cathode as a black precipitated. Nevertheless, gold recovery on cathode surface was of $25 \%$ after one hour of electrolysis. On the other hand, without the presence of sodium sulphite in ammoniacal thiosulfate solution, a gold recovery of $28 \%$ was achieved on the cathode zone. Evidently the addition of sodium sulphite helped to stabilize gold-thiosulfate but it reduced gold recovery on cathode. Gold recoveries were too low due to the presence of parasitic reactions which consume a fraction of the applied energy in the electrolytic cell.

\subsection{Electrolysis Tests Applied on Ionic Flotation Concentrates and Ammoniacal Thiosulfate Solutions}

Ammoniacal thiosulfate solutions and ionic flotation concentrates were submitted to electrolysis tests to verify if there was any impediment for the application of this technique in ion flotation froth by comparison. Gold recoveries from ammoniacal thiosulfate solution and ion flotation concentrate are shown in Fig. 5.

Tests were developed at a voltage of $0.4 \mathrm{~V}$ during one hour. It can be noticed that both experiments were very similar. Gold recovery on cathode surface from ammoniacal thiosulfate solution was of $28 \%$ whereas a gold recovery of $29 \%$ was obtained from ionic flotation concentrate. Therefore, the presence of organic reagents did not cause troubles in the development of electrolysis tests and the ionic flotation concentrate acted identically than ammoniacal thiosulfate solution. In addition a re-extraction step is not required after ion flotation.

\subsection{Effect of the Applied Current on Gold Recovery by Electrolysis}

In these tests only ionic flotation concentrates were employed and the duration of the recovery process was increased from one hour to three hours. In addition, the applied voltage to the electrolytic cell was increased since $0.4 \mathrm{~V}$ to $1.50 \mathrm{~V}$ to determine if more energy can

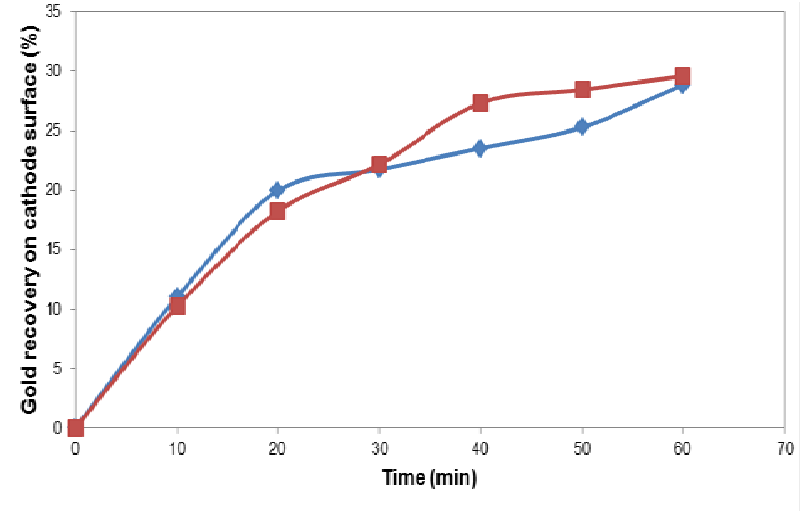

$\rightarrow$ Ammoniacal thiosulfate leachate $\quad-$ - Ionic flotation concentrate

Fig. 5 Gold recovery from amoniacal thiosulfate leachates $(0.4 \mathrm{~V} ; 12.6 \mathrm{~mA} ; \mathbf{p H}=10)$ and ionic flotation concentrates (0.4 V; $12.6 \mathrm{~mA} ; \mathrm{pH}=10)$.

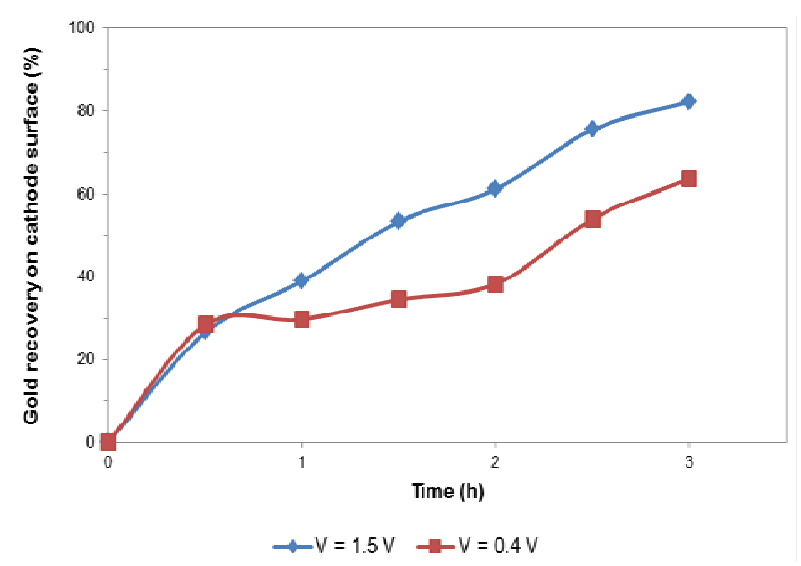

Fig. 6 Influence of the applied voltage on gold recovery from ionic flotation concentrates $(\mathrm{pH}=10)$.

deliver a higher gold recover on stainless steel cathode surface. In Fig. 6 gold recoveries on cathode zone are drawn.

At a voltage of $0.4 \mathrm{~V}$ a gold recovery of $63 \%$ was accomplished on cathode surface at the end of the third hour, whereas, with a voltage of $1.5 \mathrm{~V}$ applied to the electrolytic cell, a gold recovery of $82 \%$ was achieved in three hours of electrolysis. Obviously, an increase in the applied voltage allows to obtain a higher gold recovery on cathode zone due to more energy is available to incite gold-thiosulfate precipitation. It is important to realize that parasitic reactions are developing at the same time than gold-thiosulfate precipitation. So it is required to supply enough energy to parasitic reactions and gold-thiosulfate reduction as well. 


\section{Conclusions}

With $33 \%$ of solids concentration, a gold recovery of $80.6 \%$ was obtained in cyanidation at 24 hours and, in ammoniacal thiosulfate leaching, gold recovery was of $80.9 \%$ in just one hour. Evidently ammoniacal thiosulfate leaching is faster than cyanidation but its speed depends on an adequate equilibrium of the leaching reagents.

Ion flotation was the best technique for gold recovery from ammoniacal thiosulfate solution due to it delivered a gold recovery of $84 \%$, the highest of all proved processes. So ion flotation would be the next step after leaching process in order to extract gold from polysulphide ores.

The presence of sodium sulphite avoids the formation of gold sulfide in the electrolysis process. However, it reduced the gold recovery on cathode surface.

Gold recovery on cathode surface from ammoniacal thiosulfate solution was of $28 \%$ whereas a gold recovery of $29 \%$ was obtained from ionic flotation concentrate at a voltage of $0.4 \mathrm{~V}$. Therefore, organic reagents present in ionic flotation concentrate did not impede the normal development of electrolysis tests and it can be used after ion flotation to extract gold from froth.

A higher applied voltage is fundamental to ensure a high gold-thiosulfate reduction. That's why at a voltage of $0.4 \mathrm{~V}$ a gold recovery of $63 \%$ was obtained on cathode surface meanwhile, with a voltage of $1.5 \mathrm{~V}$, a gold recovery of $82 \%$ was achieved in three hours of electrolysis.

\section{References}

[1] Haddad, P., Grosse, A., Dicinoski, G., and Shaw, M. 2003
"Leaching and Recovery of Gold Using Ammoniacal Thiosulfate Leach Liquors." Hydrometallurgy 69 (1-3): $1-18$.

[2] Senanayake, G. 2012. "Gold Leaching by Copper (II) in Amoniacal Thiosulphate Solutions in the Presence of Additives. Part I: A Review of the Effect of Hard-Soft and Lewis Acid-Base Properties and Interactions of Ions." Hydrometallurgy 115-116 (March): 1-20.

[3] Zelinsky, A., and Novgorodtseva, O. 2013. "EQCM Study of Dissolution of Gold in Thiosulphate Solutions." Hydrometallurgy 138 (June): 79-83.

[4] Navarro, P., Villarroel, A., and Alguacil, F. 2001. "Gold Leaching with Ammonium Thiosulfate Catalyzed with Cupric Ion from a Polymetallic Concentrated." In Proceedings of the SAM-CONAMET Conferences, 93-7.

[5] Aylmore, M. G., and Muir, D. M. 2000. "Thiosulfate Leaching of Gold-A Review." Minerals Engineering 14 (2): 135-74.

[6] Ubaldini, S., Abbruzzese, C., Fornari, P., Massida, R., and Veglio, F. 1995. "Thiosulfate Leaching for Gold Hydrometallurgy." Hydrometallurgy 39 (1-3): 265-76.

[7] Navarro, P., Vargas, C., Alonso, M., and Alguacil, F. 2006. "The Adsorption of Gold on Activated Carbon from Thiosulfate-Ammoniacal Solutions." Gold Bulletin 2006 39 (September): 93-7.

[8] Guerra, E., and Dreisinger, D. B. 1999. "A Study of the Factors Affecting Copper Cementation of Gold from Ammoniacal Thiosulfate Solution." Hydrometallurgy 51 (February): 155-72.

[9] Hiskey, J., and Lee, J. 2003. "Kinetics of Gold Cementation on Copper in Ammoniacal Thiosulfate Solutions." Hydrometallurgy 69 (1-3): 45-56.

[10] Fujita, T., Kejun, L., Tai Yen, W., Shibayama, A., and Miyazaki, T. 2004. "Gold Extraction from Thiosulfate Solution Using Trioctyl Methyl Ammonium Chloride." Hydrometallurgy 73: 41-53.

[11] Serrano, J. 2012. "Plant Design for Gold Recovery from Sulfurized Ores with Dithiooxamide as Low Toxicity Leaching Reagent." In Proceedings of the Certification Project Previous The Obtention of Chemical Engineer Title, 56-7 (Escuela Politécnica Nacional, Quito, Ecuador). 